\title{
The change in the morphology of the blasted surface after phosphating and cataphoretic coating
}

\author{
Brezinová J., Guzanová A., Draganovská D., Brezina J., Viňáš J. \\ Department of Technologies, Materials and Computer Aided Production, \\ Faculty of Mechanical Engineering, Technical University of Kosice, Slovakia \\ E-mail: janette.brezinova@tuke.sk
}

The paper focuses on the quality of coatings applied by cataphoretic deposition and cataphoretic deposition technology with a phosphate layer. The quality of the coatings was evaluated by determining the roughness of the coatings, the morphology of the coatings, spectral analyses were performed detecting the presence of individual elements in the coatings. There was analysed also defect-uncoated spot.

\section{INTRODUCTION}

Protection of metals with various types of coatings is one of the most important ways of protecting a material against corrosion. The coating applied to the base material acts as a barrier against a corrosive environment. In order to provide sufficient anti-corrosion protection of the surfaces by the coatings, it is necessary to ensure an adequate quality of the surface pre-treatment of the materials before the application of the coatings. One possibility is abrasive cleaning of the surface, where by using optimal technological parameters of the process and suitable choice of abrasive it is possible to achieve the required cleanliness and at the same time optimal microgeometry of the base material (for cleaning and roughening before coating it is suitable to use angular abrasive). [1-4]

Various types of surface treatments can then be applied to a suitably prepared surface. Phosphating is a chemical treatment of the surface of metals, in which insoluble tertiary phosphate is formed from tertiary soluble phosphate of zinc, manganese, calcium or iron. Phosphating significantly improves the adhesion of coatings, their corrosion resistance and resistance to corrosion. Phosphate is characterized by very good adhesion, good sliding properties, it is an economically advantageous process. It is used to increase the corrosion resistance, also as a base for the application of coatings, or as a coating facilitating the running-in of rotating parts of equipment, or as a reservoir for lubricant in deep drawing. [5-8]
Cataphoretic coating is one of the two types of electrophoretic coating. Today, it is perceived as one of the modern technologies for surface treatment of metal parts, which is characterized by a highly economical and environmentally friendly method of application and is one of the progressive production technologies for coating with a high degree of corrosion protection of metals. Due to its high anti-corrosion efficiency, it is used e.g. in the automotive industry for surface protection of steel, galvanized, aluminium or stainless steel parts. The surface to which such a coating is applied must be suitably prepared - cleaned and for better adhesion it is necessary to create a base conversion phosphate layer. [9-12]

The cataphoretic application of the protective coating is based on the migration and subsequent neutralization of the epoxy-polyurethane or acrylate resin, present in ionic form in aqueous solution, on the cathode - i.e. the coated product. Simultaneously with the migration of the dye cation and its counter anion, the decomposition of water takes place and the newly formed hydroxyl anion immediately on the surface of the cathode neutralizes the dye cation and converts it into an insoluble molecular form. The film thus deposited can be rinsed with demineralized water with a low solvent content without losing the already deposited layer and polymerized. In this way, it acquires the required properties.

Cataphoretic coating deposition can be used as a final - single layer coating or as a suitable base for further coatings. Among the fundamental advantages of the process we rank the very nature of the process - it is an electrochemical process operating in the molecular dimension, which fundamentally positively affects the properties of the coating thus formed. In this way, a high corrosion resistance is achieved with a relatively small coating thickness (approx. $25 \mu \mathrm{m}$ ) as well as a uniformity of the deposited layer. From an environmental point of view, this is a minimal burden, as the content of organic 
solvents in the bath is below $1 \%$ and application losses are also minimized. However, it is necessary to state an important limiting factor of cataphoresis - it is possible to apply this technology only to an electrically conductive and bath-immersible product, which must withstand curing polymerization temperature $\left(\min .160^{\circ} \mathrm{C}\right)$. [13]

The paper deals with testing the effect of phosphating on the resulting roughness of the cataphoretic layer, as well as the analysis of the formation of a defect in the cataphoretic layer.

\section{MATERIALS AND METHODS}

For the experiment, S355J2 $+\mathrm{N}$ steel was used as the base material. Chemical composition of base material is given in Tab. 1.

The surface preparation of the samples was carried out mechanically - by abrasive grit blasting with an ABSC 1440 pressure blasting device. Steel grit with a grain size of $0.4 \mathrm{~mm}$ was used as an abrasive. This cleaned the surface and at the same time activated it and obtained a suitable geometry for optimal mechanical anchoring of the subsequently applied coatings.

The surface treatment of the samples was applied in two ways:

1) Phosphating, parameters are given in Tab. 2, using Chemfos 700 RGI + Chemfil Butter / M + Chemfos Additive Liquid. Chemfos is a dual action chemical process which can be used to simultaneously clean and deposit an zinc phosphate on steel substrates prior to painting. Chemfos can be used to process steel as well as aluminium and zinc substrates.

2) Application of cataphoretic coating POWERCRON $6200 \mathrm{HE}$ KTL. It is a modern cathodic epoxy electrophoretic coating without heavy metals, applicable by passing a direct current to a steel surface with a layer of zinc phosphate. It is a mixture of synthetic resin, pigment paste, organic solvents and other chemical additives. It shows excellent corrosion resistance on zinc phosphate substrate without the use of chromium passivation. Improves the adhesion of other coatings on metal substrates.

The process parameters are listed in Tab. 3 .

The combinations of surface treatments and the derived labelling of the samples were as follows:

- blasting and phosphating: $\mathrm{PH}$,

- blasting and cataphoretic coating: KTL,

- blasting, phosphating and cataphoretic coating: $\mathrm{PH}+$ + KTL.

The methodology of sample evaluation was as follows:

1. The roughness of the coatings was evaluated using stylus profilometer Surftest SJ-201. The measurement parameters were as follows:

- a measured profile: $\mathrm{R}$,

- a filter: GAUSS,

- a sampling length $\lambda \mathrm{c}=0,8 \mathrm{~mm}$,

- a number of sampling lengths $\mathrm{N}=5$,

- an evaluation length $\ln =4 \mathrm{~mm}$,

- a number of measurements: 30 .

Tab. 1. Chemical composition of base material [wt. \%]

\begin{tabular}{|c|c|c|c|c|c|c|c|}
\hline $\mathbf{C}$ & $\mathbf{S i}$ & $\mathbf{M n}$ & $\mathbf{P}$ & $\mathbf{S}$ & $\mathbf{N}$ & $\mathbf{C u}$ & $\mathbf{F e}$ \\
$\max$ & $\max$ & $\max$ & $\max$ & $\max$ & $\max$ & $\max$ & balance \\
\hline 0.20 & 0.55 & 1.60 & 0.025 & 0.025 & - & 0.40 & \multicolumn{2}{c|}{ b } \\
\hline
\end{tabular}

Tab. 2. Phosphating parameters

\begin{tabular}{|c|c|c|c|c|c|c|}
\hline \multicolumn{6}{|c|}{ Chemfos 700 RGI + Chemfil Butter/M+Chemfos Additive Liquid + demineralised water } \\
\hline Temperature & Free acid & Total acid & Zn content (ppm) & Ni content (ppm) & Mn content (ppm) & Accelerator (pts gas) \\
\hline $51^{\circ} \mathrm{C}$ & 1 & 24 & 1300 & 700 & 700 & 1.3 \\
\hline
\end{tabular}

Tab. 3. Parameters of cataphoretic application of POWERCRON 6200 HE KTL

\begin{tabular}{|c|c|c|c|c|c|c|c|}
\hline \multicolumn{9}{|c|}{ Binder CR 693A / Pigment paste CP 471A } & \multicolumn{2}{c|}{ Anolyte } \\
\hline Temp. & $\begin{array}{c}\text { Dry basis } \\
\left(1 \text { hour } / 10^{\circ} \mathrm{C}\right)[\%]\end{array}$ & $\begin{array}{c}\mathrm{pH} \\
\left.\text { (at } 25^{\circ} \mathrm{C}\right)\end{array}$ & $\begin{array}{c}\text { Conductivity } \\
\left(\text { at } 25^{\circ} \mathrm{C}\right)[\mu \mathrm{S} / \mathrm{cm}]\end{array}$ & $\begin{array}{c}\mathrm{pH} \\
\left(\text { at } 25^{\circ} \mathrm{C}\right)\end{array}$ & $\begin{array}{c}\text { Conductivity } \\
\left(\text { at } 25^{\circ} \mathrm{C}\right)[\mu \mathrm{S} / \mathrm{cm}]\end{array}$ & $\begin{array}{c}\mathrm{pH} \\
\left(\text { at } 25{ }^{\circ} \mathrm{C}\right)\end{array}$ & $\begin{array}{c}\text { Conductivity } \\
\left(\text { at } 25^{\circ} \mathrm{C}\right)[\mu \mathrm{S} / \mathrm{cm}]\end{array}$ \\
\hline 35 & 17.00 & 5.30 & 1800 & 5.1 & 1000 & 3.5 & 6000 \\
\hline
\end{tabular}


The surfaces were evaluated by parameters in accordance with the standard STN EN ISO 4287:

- the arithmetical mean deviation of the assessed profile (Ra),

- the maximum height of profile on the basic length (Rz),

- the total height of the profile on the evaluation length (Rt).

2. REM analysis, EDX analysis, line EDX analyses and coating thickness - a Jeol JSM 7000F scanning electron microscope with an EDX Oxford analytical unit and a ZEISS EVO M15 electron microscope were used for coating analysis and local chemical element analysis. Samples for surface morphology evaluation and thickness

Tab. 4. Average roughness values of surfaces, coating

\begin{tabular}{|l|c|c|c|}
\hline Sample & Ra $[\boldsymbol{\mu m}]$ & $\mathbf{R z}[\boldsymbol{\mu m}]$ & $\mathbf{R t}[\boldsymbol{\mu m}]$ \\
\hline $\begin{array}{l}\text { Abrasive blasted } \\
\text { surface }\end{array}$ & $6.79 \pm 0.53$ & $33.37 \pm 2.64$ & $42.39 \pm 5.75$ \\
\hline PH + KTL & $3.91 \pm 0.50$ & $16.31 \pm 3.01$ & $25.54 \pm 5.84$ \\
\hline KTL & $4.08 \pm 0.46$ & $16.37 \pm 2.24$ & $26.42 \pm 3.47$ \\
\hline
\end{tabular}

measurement were prepared in PolyFaste conductive dentacryle, ground and polished with diamond paste on satin moistened with kerosene, washed and rinsed with gasoline alcohol. The samples were sonicated in methanol. Coating thicknesses were determined on a cross section of the samples.

\section{RESULTS AND DISCUSSION}

In terms of the above methodology, the roughness of the samples was evaluated by the stylus contact method. The results of roughness measurements are shown in Table 4, the profilograms are shown in Fig. 1.

Tab. 4 shows that the roughness values ( $\mathrm{Ra}, \mathrm{Rz}$ ) decrease after the application of the coatings compared to the roughness of the uncoated blasted surface. The average surface roughness $\mathrm{Ra}$ of the blasted surface was $6.79 \mu \mathrm{m}$, decreased to $4.08 \mu \mathrm{m}$ after applying the KTL coating, and decreased to $3.91 \mu \mathrm{m}$ after applying the phosphate layer and the KTL coating. The shape of the surface after the application of KTL partially repeats the shape of the blasted surface, but there is a partial suppression of the micro-irregularities of the surface as can be seen from the profilograms (Fig. 1) and from the cross-sections (Fig. 2).

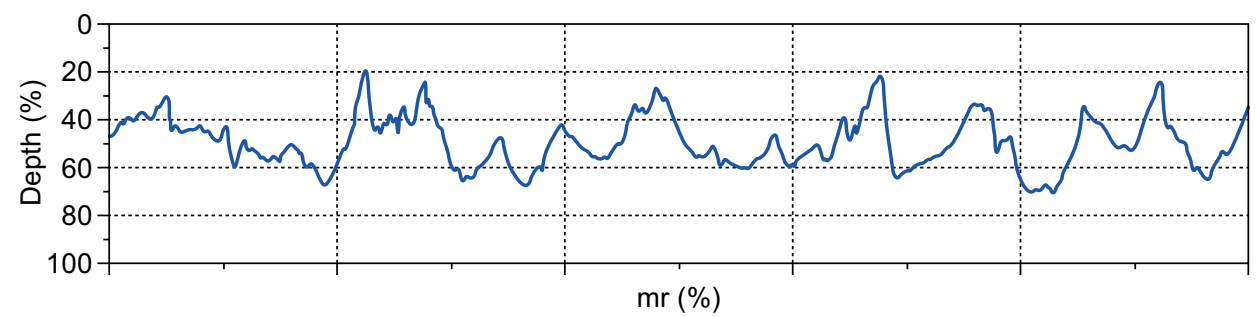

a) surface treated by abrasive blasting and phosphate layer $\mathrm{PH}$

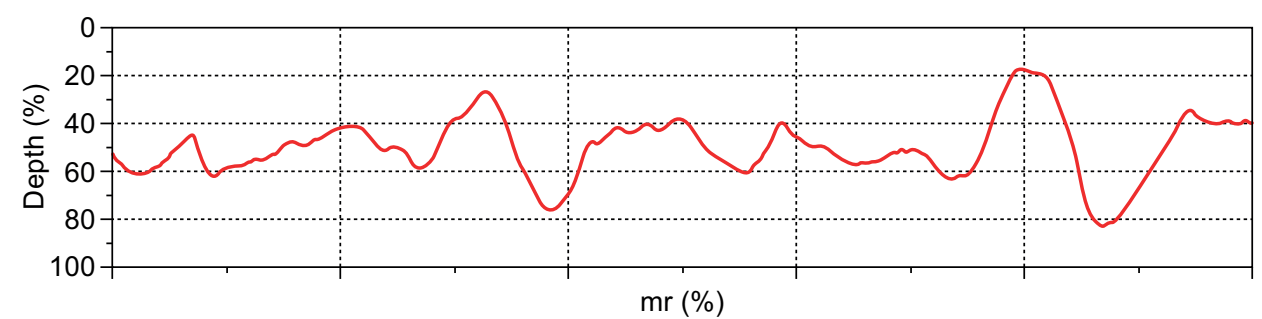

b) surface treated by abrasive blasting and KTL

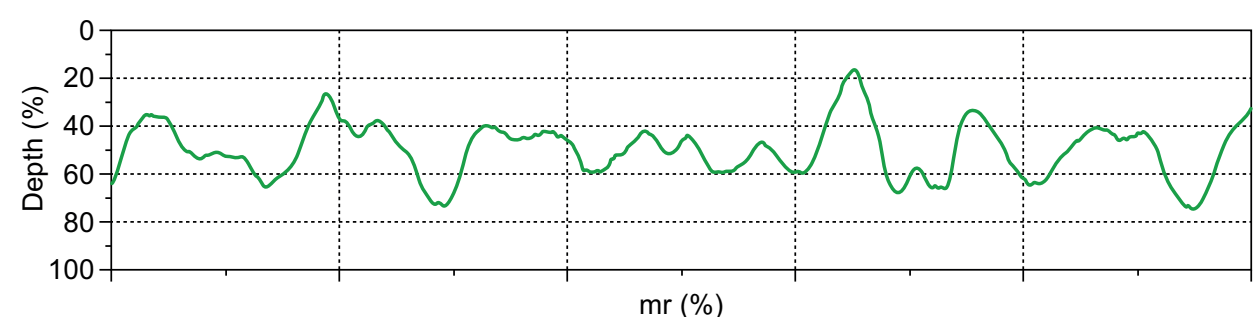

c) surface treated by abrasive blasting, $\mathrm{PH}$ ad KTL
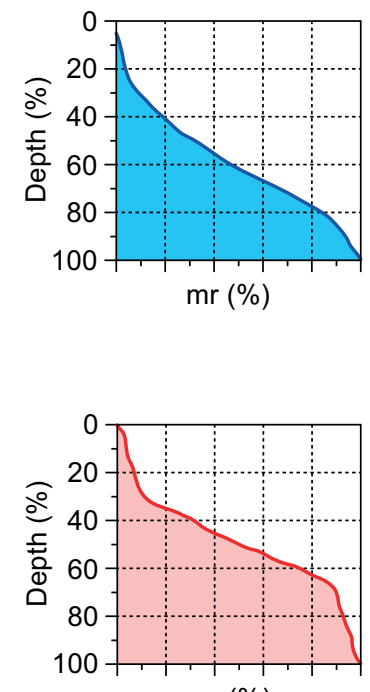

$\mathrm{mr}(\%)$

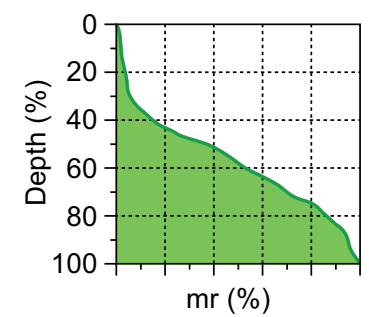

Fig. 1. Profilograms of evaluated surfaces 


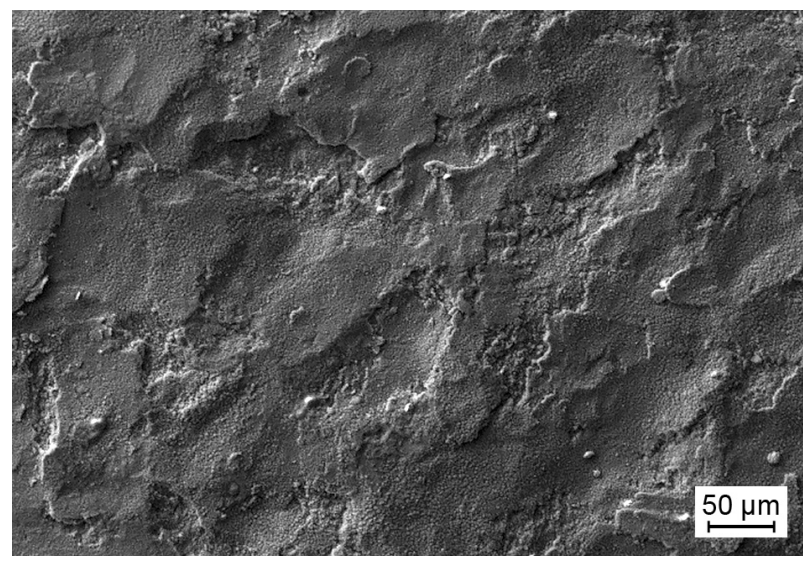

a)

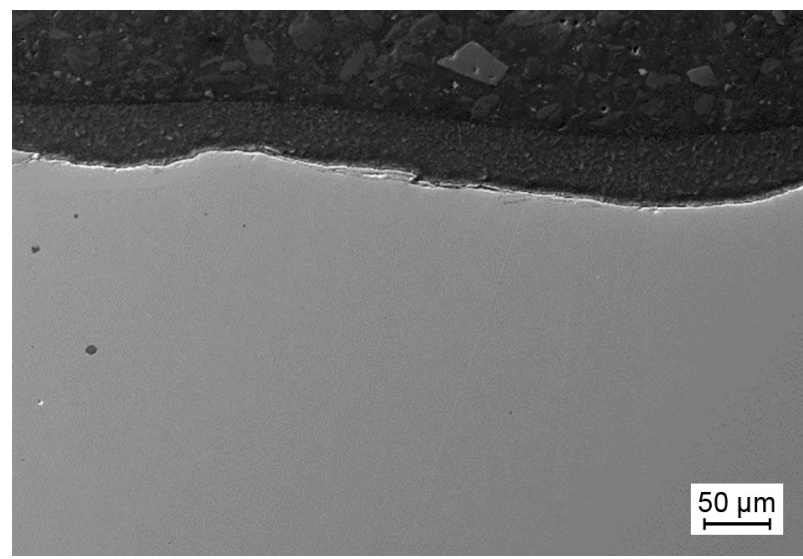

c)

Fig. 2. Cross section through surfaces and coatings

EDX analysis of the phosphate coating is shown in Fig. 3. This pointed to the presence of elements typical for steel and the phosphate layer (zinc phosphate).

Fig. 4 shows a cross-sectional view of KTL and $\mathrm{PH}+\mathrm{KTL}$ coatings. The thickness of these coatings at individual magnifications is also indicated. On the cross section of the KTL coating there is a clear interface between the blasted surface and the KTL coating, the KTL coating perfectly copies the blasted surface, the coating has filled all the micro-irregularities on the

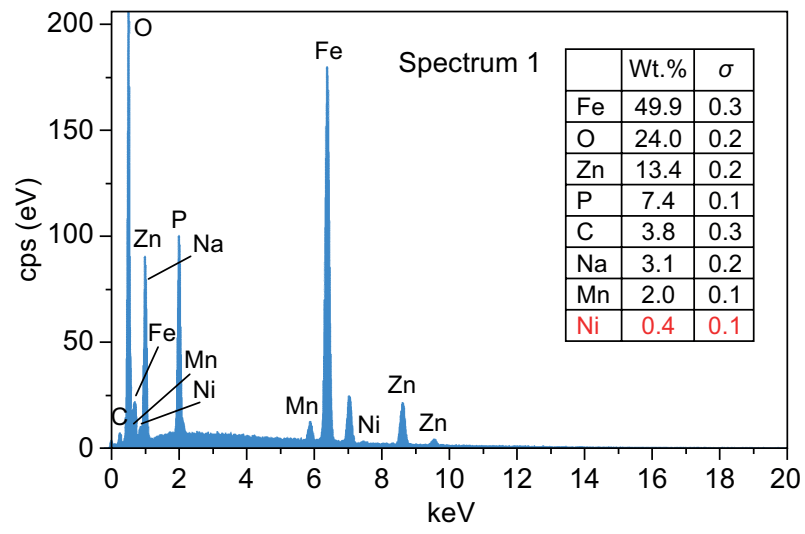

Fig. 3. EDX analysis of phosphate layer PH

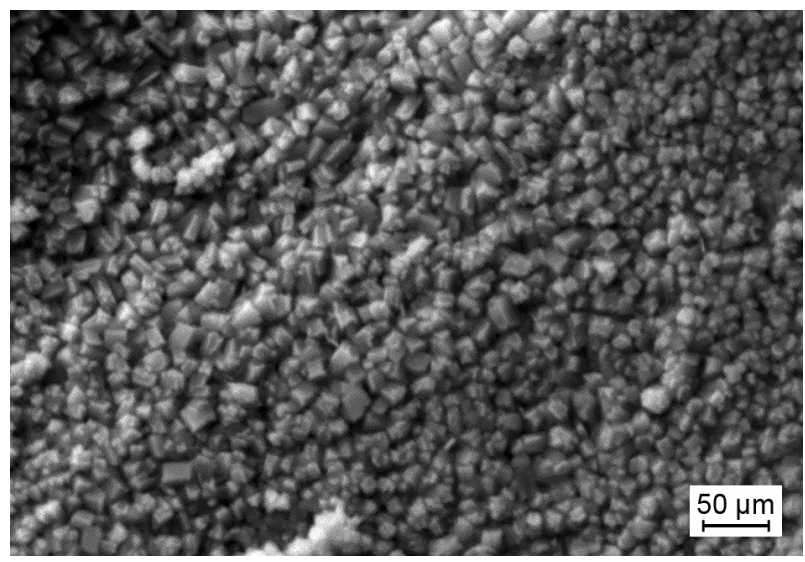

b)

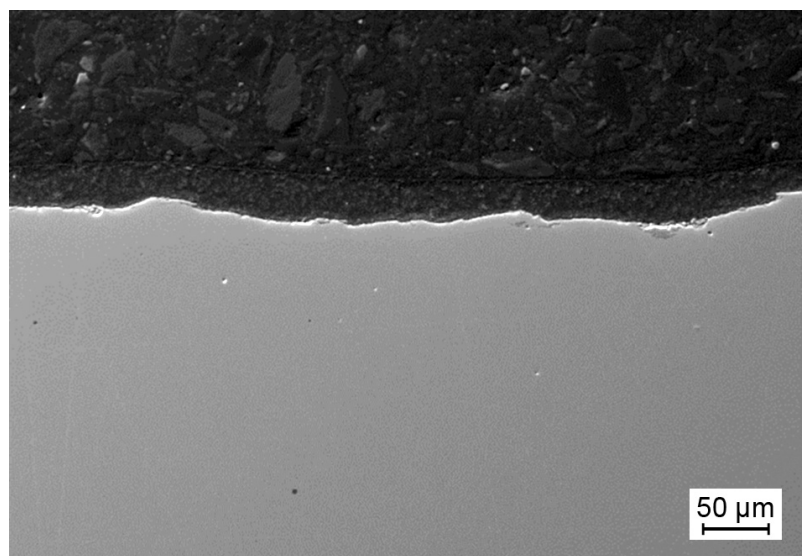

d)

blasted surface. The thickness of the KTL coating is about of $38 \mu \mathrm{m}$.

On the cross section of the F + KTL coating, there is a clear interface where there is a phosphate layer between the blasted surface and the KTL coating. The phosphate layer ensures the adhesion of the KTL layer by increasing the contact area. The adhesion of the phosphate to the steel is ensured by the chemical reaction of the steel with the phosphating solution, i.e. the individual crystals are a reaction product firmly bound to the substrate. The thickness of the KTL coating is approximately $31 \mu \mathrm{m}$. The thickness of the phosphate layer is about $1 \mu \mathrm{m}$, although the thickness of the phosphate layer is standardly given in $\mathrm{g} \mathrm{m}^{-2}$.

Fig. 5 shows line EDX analyses across the base material - KTL interface and the base material - PH + + KTL coating interface. The analyses present the distribution of individual elements along the interface.

At the location of the phosphate layer at the $\mathrm{PH}+$ + KTL coating, increased amounts of mainly $\mathrm{O}, \mathrm{Zn}$ and $\mathrm{P}$ elements were detected, which confirms the presence of this layer under the KTL coating and it is possible to determine the thickness of the phosphate layer, which is about of $1 \mu \mathrm{m}$. 


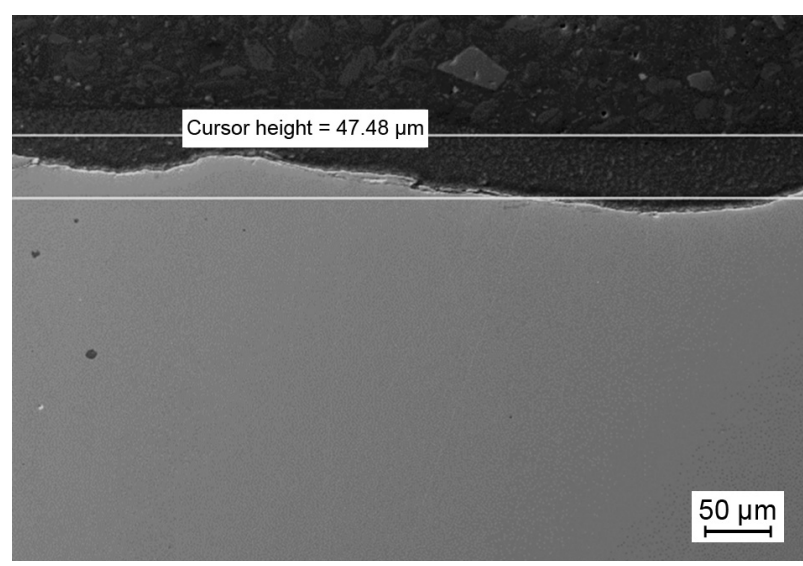

a)

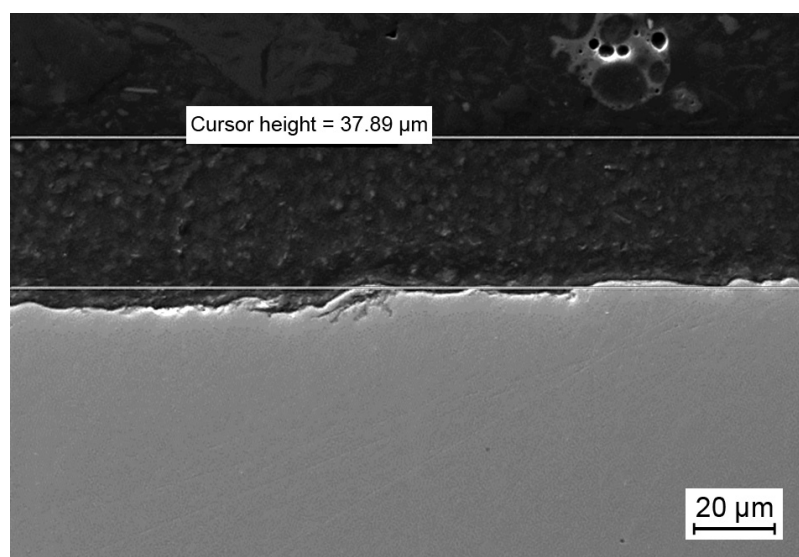

c)

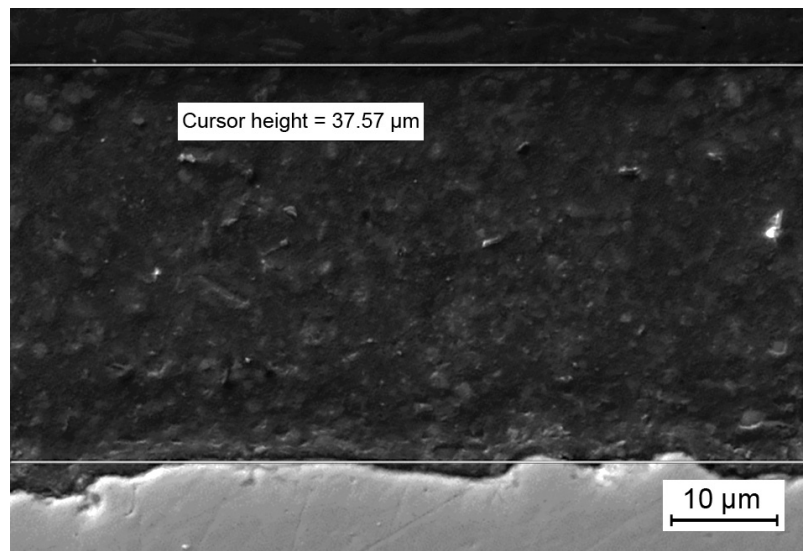

e)

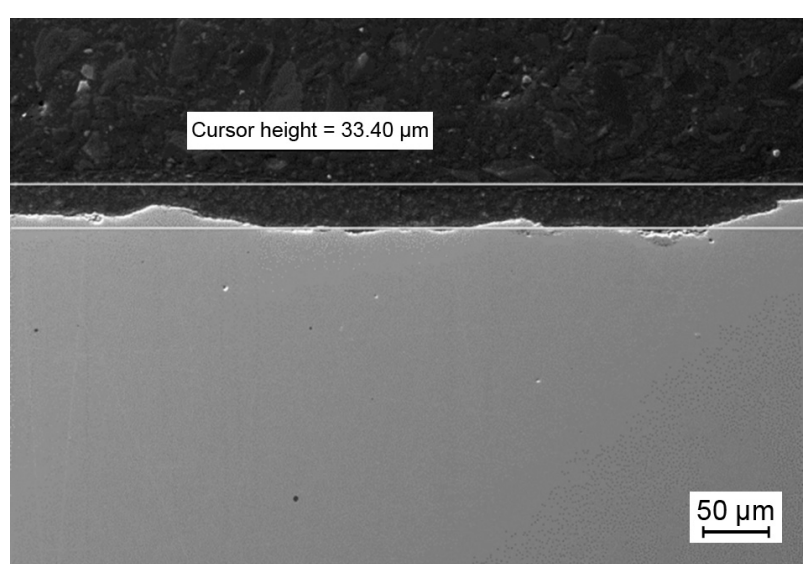

b)

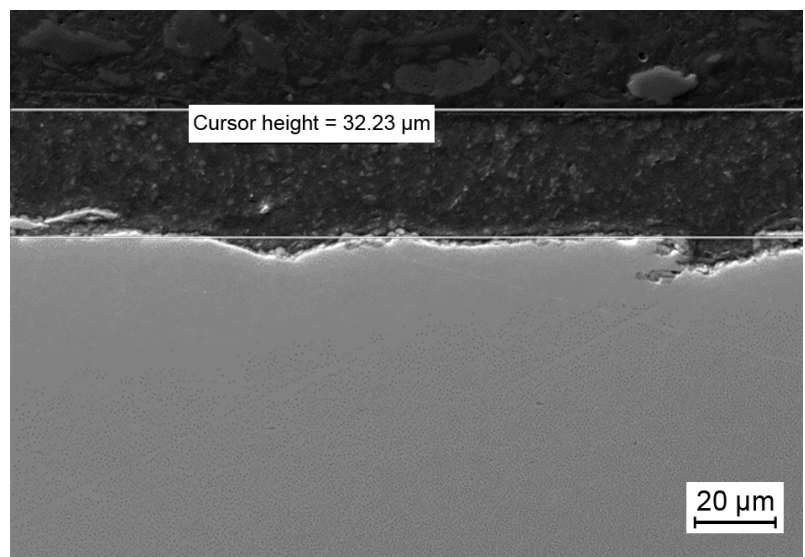

d)

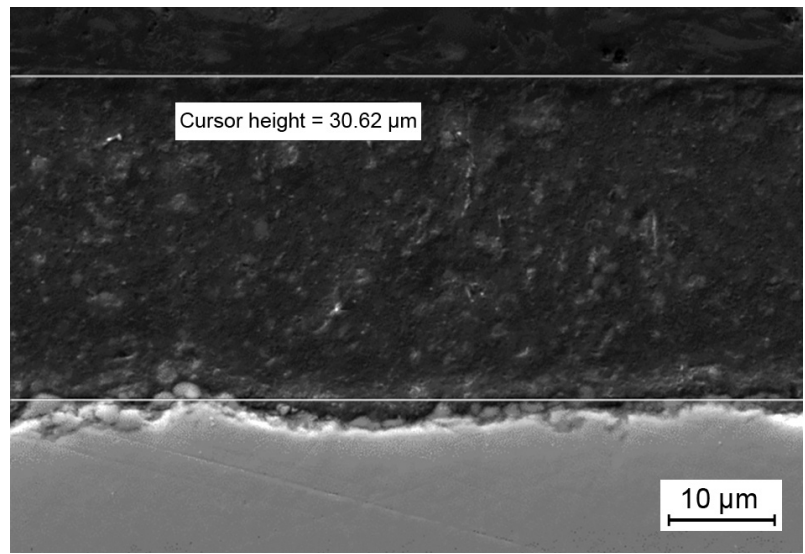

f)

Fig. 4. Cross section of coated samples, REM analysis and thickness determination

Spectral analyses detecting the presence of individual elements were performed on the cross section of the KTL layer as well as the PH + KTL layer, Fig. 6 .

In the KTL coating, spectrum 23 corresponds to the base material, spectrum 22 corresponds to the interface between the KTL and the base material, and spectrum 24 corresponds to the KTL coating.

On the cross section of the F + KTL coating, the spectrum 20 determined by spectral analysis corresponds to the base material, the spectrum 19 to the phosphate layer and the spectrum 21 corresponds to the KTL coating.

Defects can occur during the application of coatings, especially if the parameters of the technological process are not observed. Fig. 7 shows the appearance of the $\mathrm{PH}$ + KTL coating around the defect - an uncoated spot.

The PH + KTL coating defect arose in the technological process between phosphating and KTL coating. In the uncovered part of the defect, a substrate with an evenly formed phosphate layer is visible. 

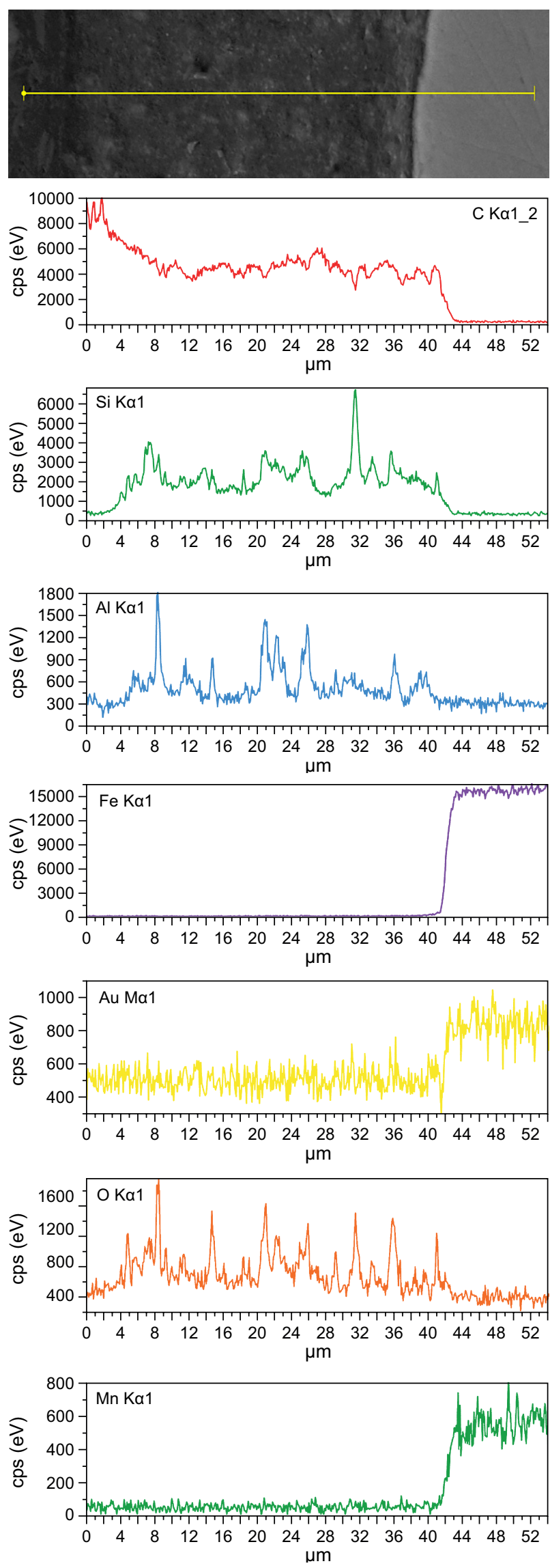
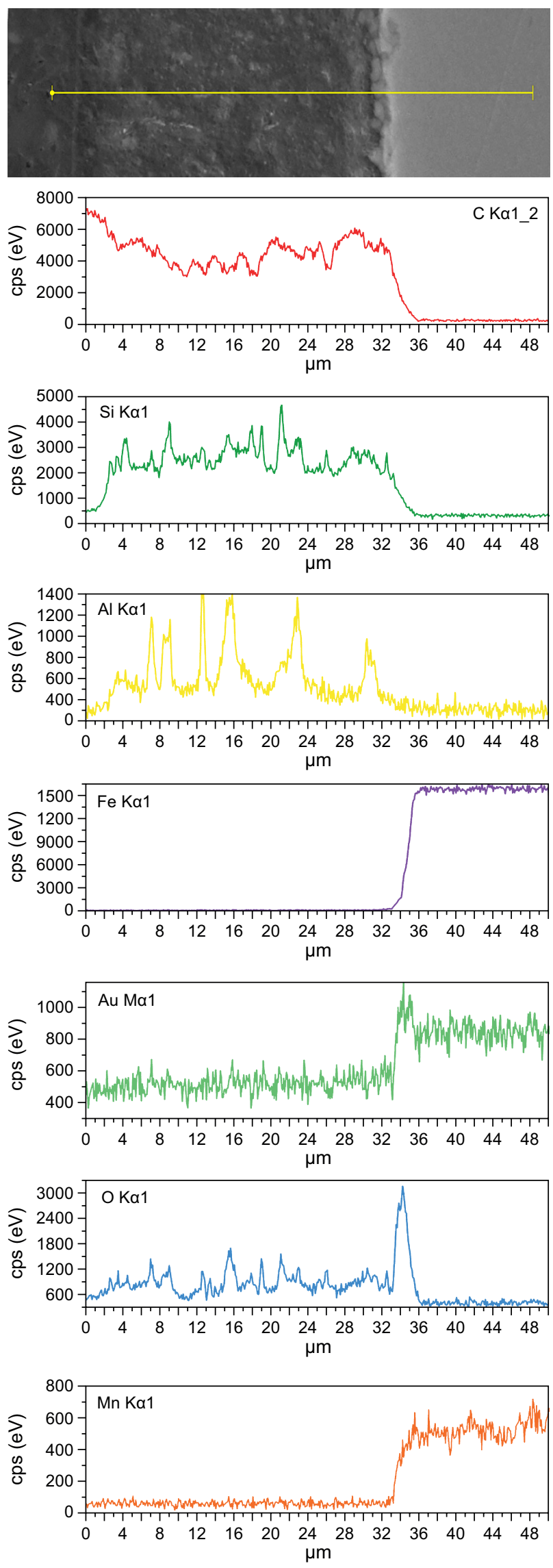

Fig. 5. Line EDX analyses of interface between base material KTL (left) and PH+KTL (right) - Continue on next page 

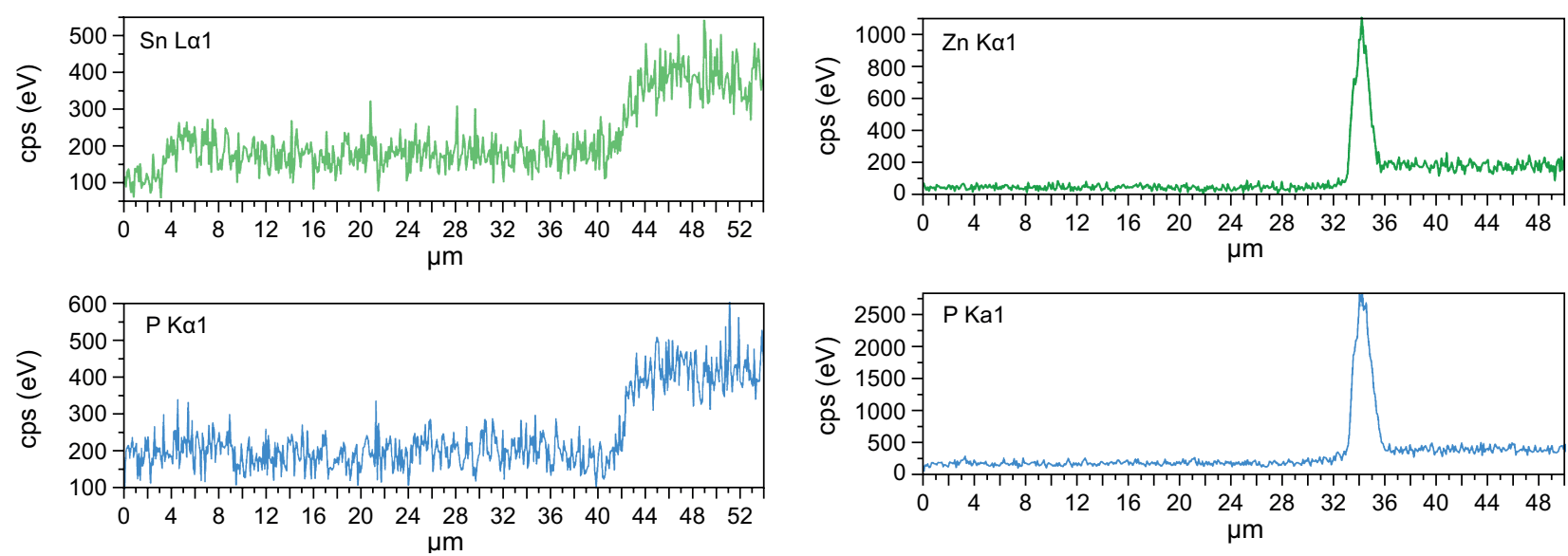

Fig. 5. Line EDX analyses of interface between base material KTL (left) and PH+KTL (right)

In general, oily, waxy or silicone residues, insufficient cleaning of the substrate surface, wet surface, residues from pre-treatment or previous operation are considered to be the causes of such a defect. Based on the shape of the defect - drop, it is possible to assume that the technology used in operation could have been either contamination of the KTL coating with acid from phosphating, or contamination of the phosphate layer before the application of KTL. In the process of applying
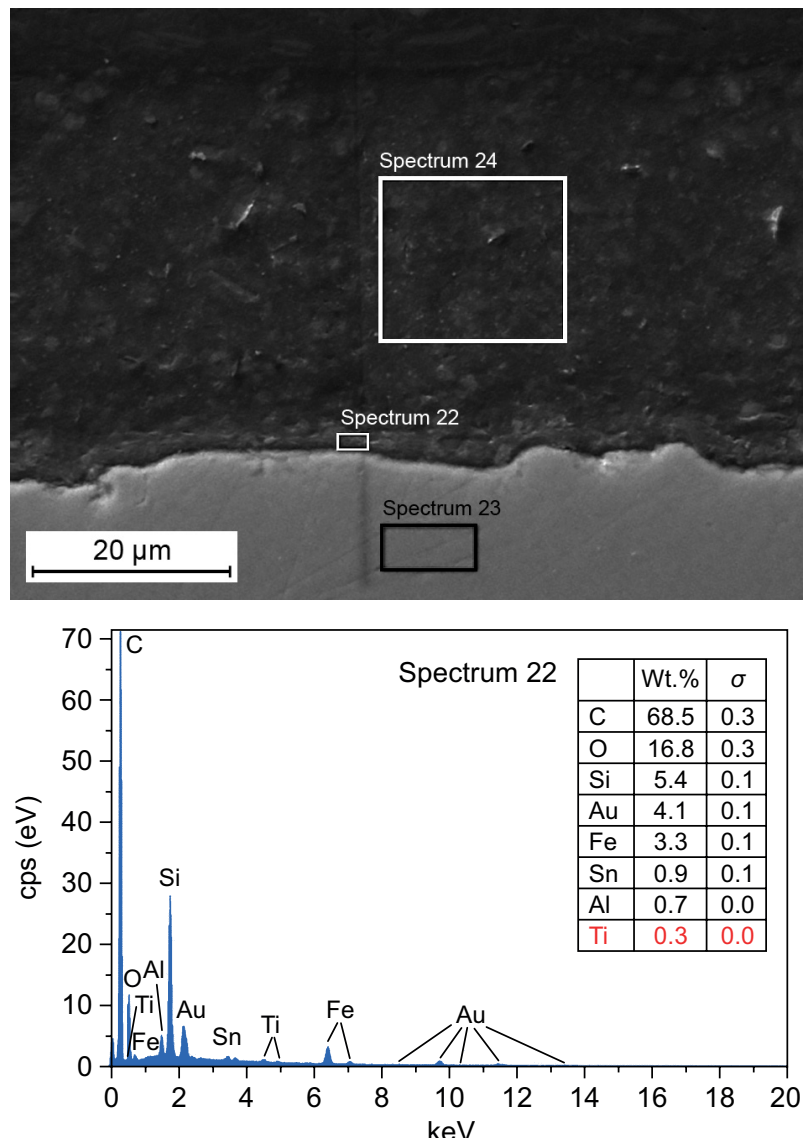

surface treatments, operating fluids may have been sprayed on the treated surfaces.

Another cause of the observed defect may be the adhesion of air bubbles in the process of cataphoretic dip coating, which causes locally uncoated areas. Such defects occur mainly on the bottom surfaces of horizontal parts due to their imperfect deaeration during immersion. This problem can be solved by positioning the product in the bath.

Fig. 6. Spectral EDX analysis of KTL (left) and PH+KTL (right) coating and base material - Continue on next page 

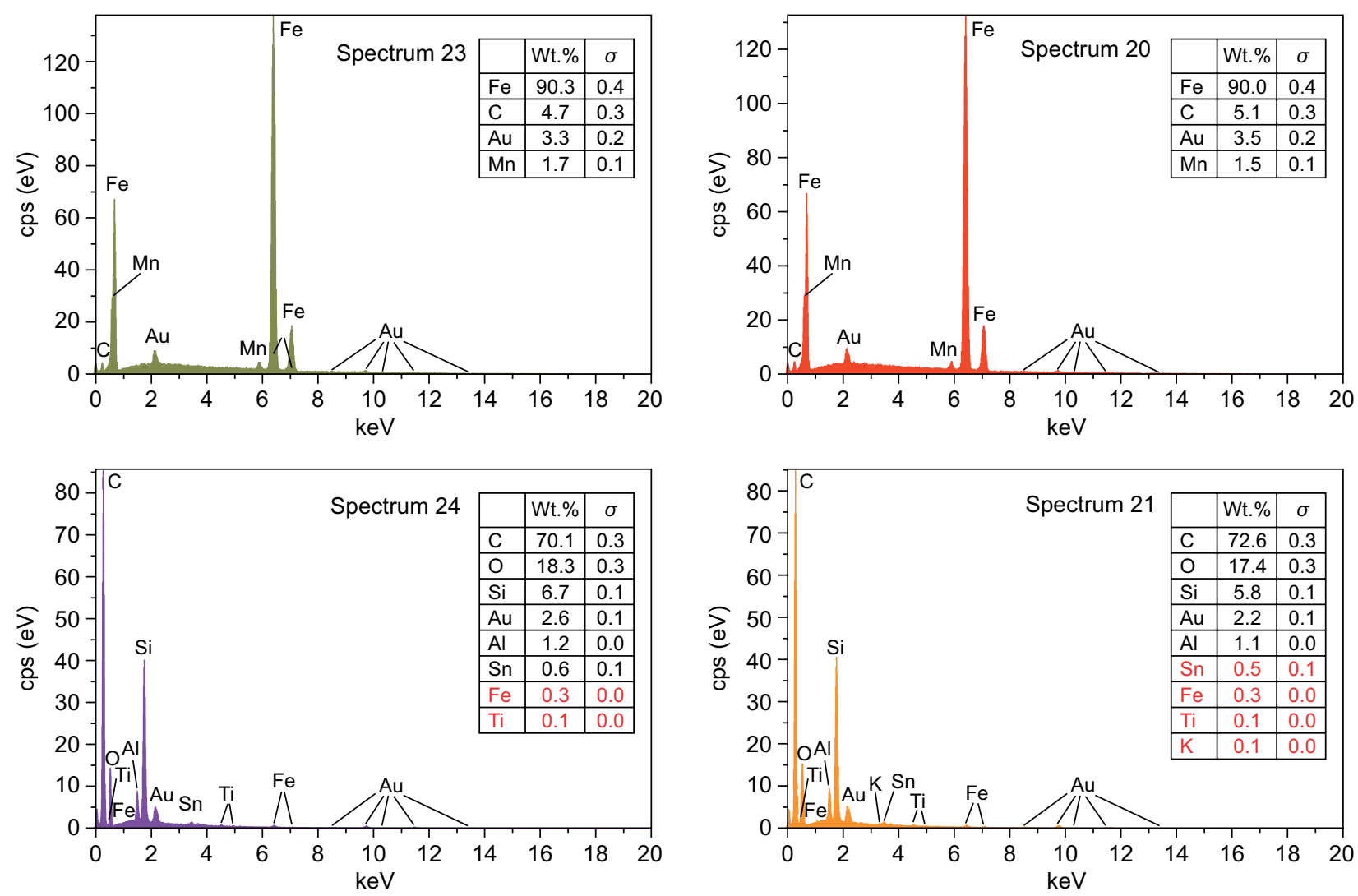

Fig. 6. Spectral EDX analysis of KTL (left) and PH+KTL (right) coating and base material

These claims of defects are supported by EDX maps of the distribution of individual elements (see Fig. 8).

\section{CONCLUSIONS}

Based on the performed analyses of various types of surfaces and coatings - blasted and subsequently phosphated, surface blasted with KTL coating and surface blasted with phosphate and KTL coating, it is possible to formulate the following conclusions:

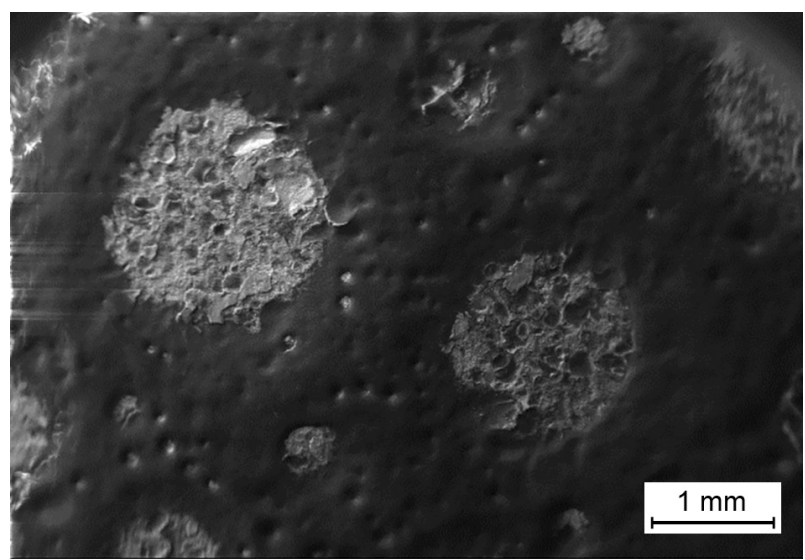

a)
- The roughness values ( $\mathrm{Ra}, \mathrm{Rz}$ ) decrease after the application of the coatings compared to the blasted surface. The average value of the roughness Ra of the blasted surface was $6.79 \mu \mathrm{m}$, after the application of the KTL coating it decreased to $4.08 \mu \mathrm{m}$ and after the application of the phosphate layer and the KTL coating it decreased to the value of $3.91 \mu \mathrm{m}$. The surface after the application of KTL partially copies the shape of the blasted surface, but the micro-irregularities of the surface are reduced.

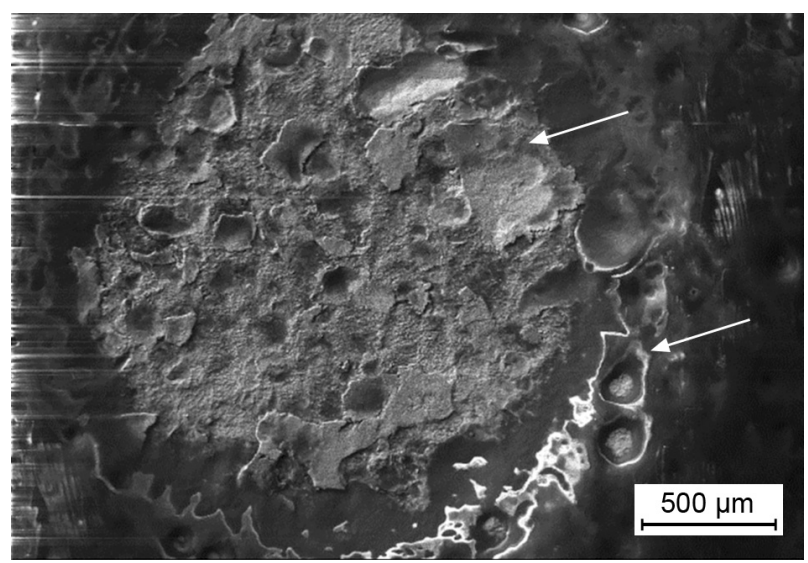

b)

Fig. 7. Appearance of the coating near the defect (SEM) - Continue on next page 


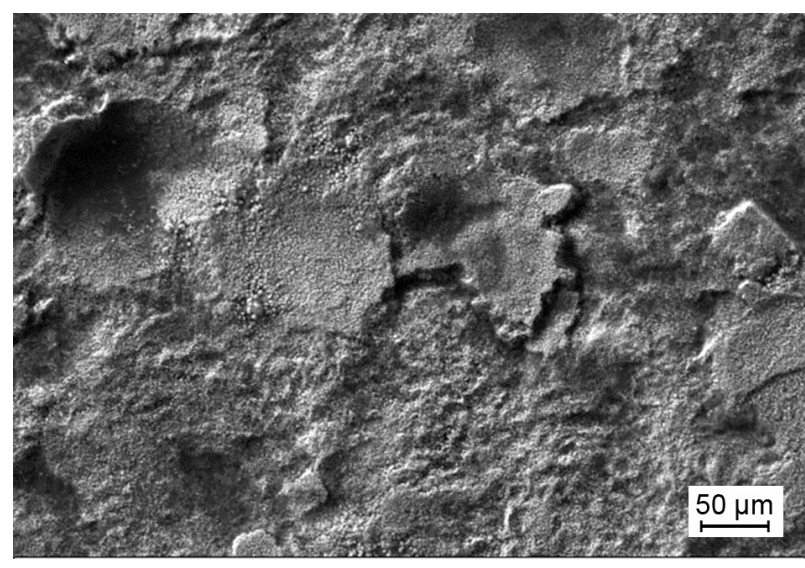

c)

Fig. 7. Appearance of the coating near the defect (SEM)
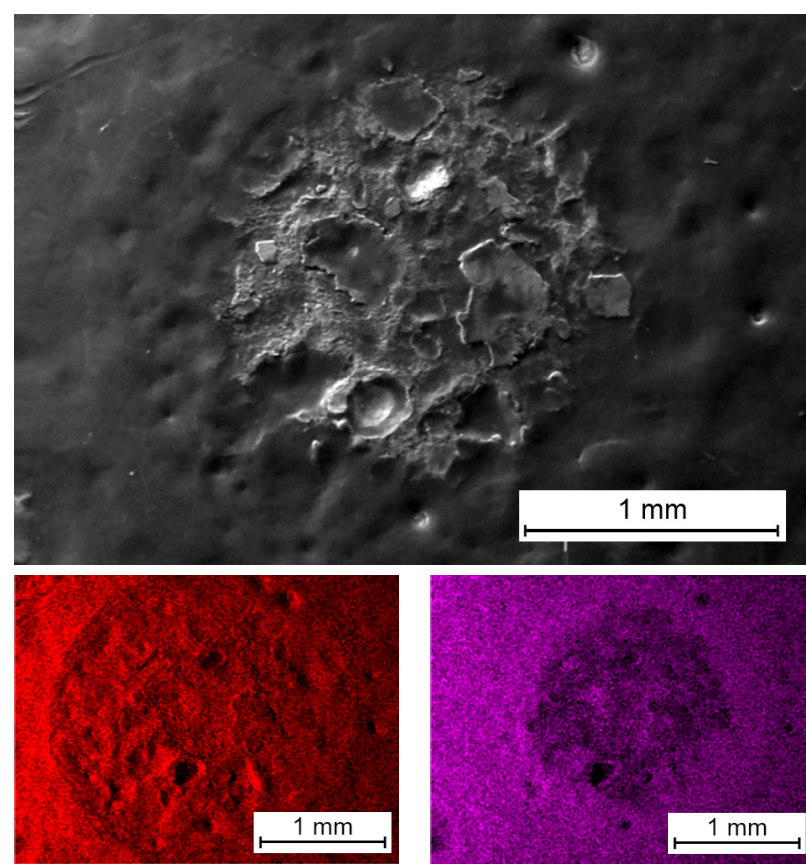

C Ka1

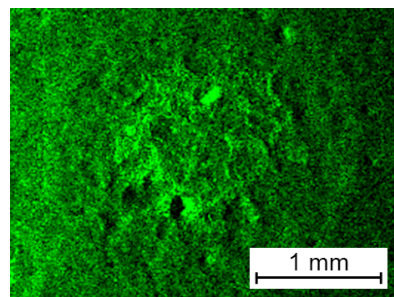

O Ka1

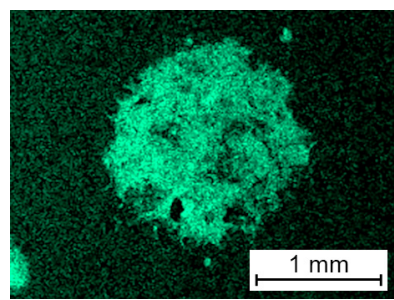

P Ka1

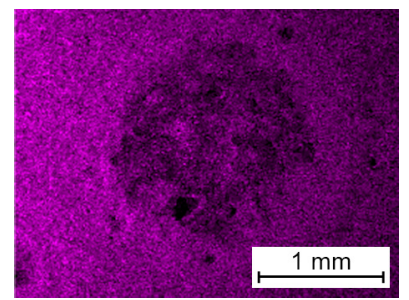

Si Ka1

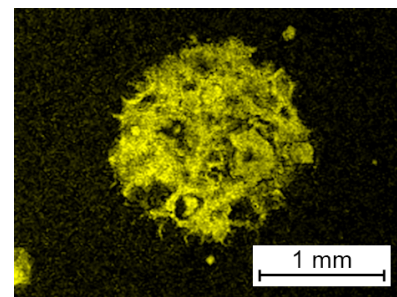

Fe Ka1

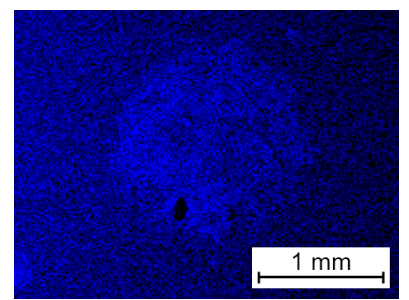

Au Ma1

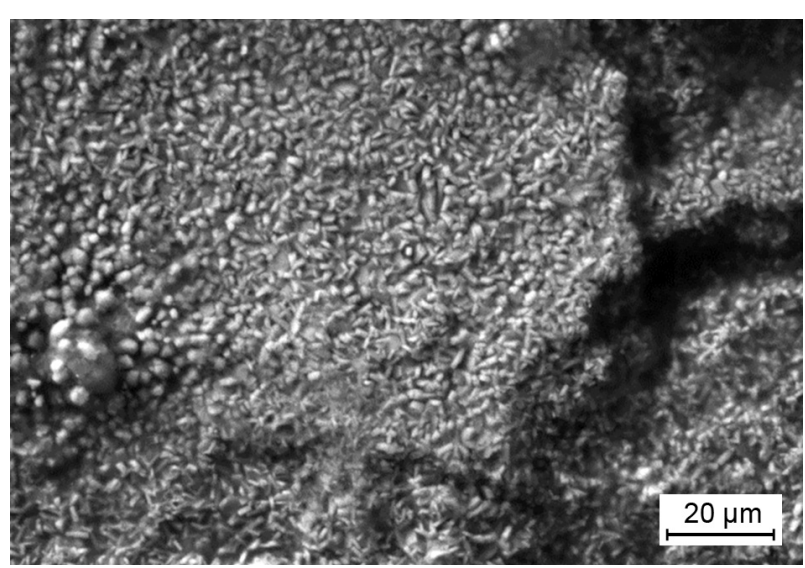

d)

- The average thickness of the KTL coating was $38 \mu \mathrm{m}$, the thickness of the KTL coating deposited on the PH $+\mathrm{KTL}$ sample is $31 \mu \mathrm{m}$, the thickness of the phosphate layer is about $1 \mu \mathrm{m}$.

- No KTL coating was applied at the defect site on the analysed sample, only the presence of a phosphate layer was observed. This is probably the adhesion of air bubbles in the process of cataphoretic dip coating. Such coating defects are due to imperfect deaeration during immersion. It is therefore necessary to pay attention to the positioning of the product in the bath during application.

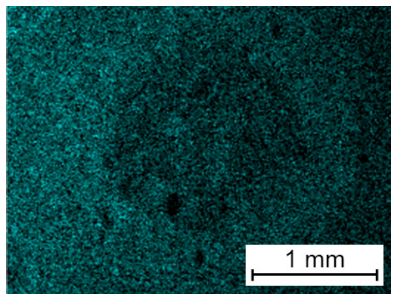

Al Ka1

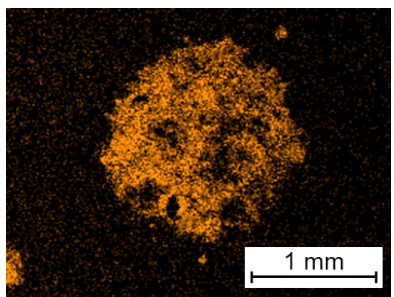

Zn Ka1

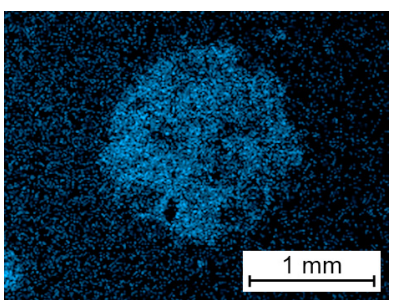

Mn Ka1

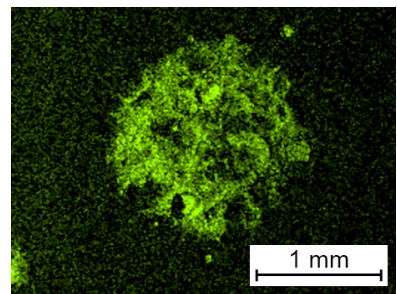

Na Ka1_2

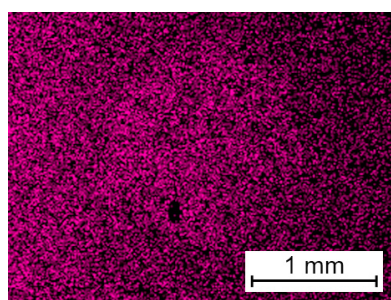

Sn La1

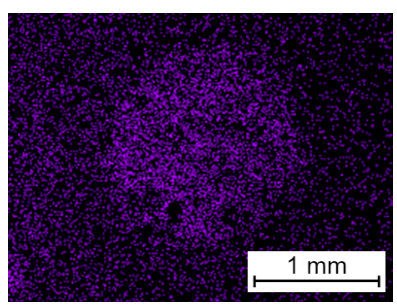

Ni Ka1

Fig. 8. EDX maps of elements distribution at the defect of the KTL coating 


\section{Acknowledgements}

This work was supported by the Ministry of Education, Science, Research and Sport of the Slovak Republic (VEGA No. 1/0154/19 and VEGA No. 1/0497/20).

\section{REFERENCES}

1. Brezinová J., Guzanová, A., Draganovská D.: Abrasive Blast Cleaning and Its Application, Pfaffikon, Trans Tech Publications 2015, 107 p.

2. Brezinová J. et al.: Korózia materiálov a špeciálne technológie povrchových úprav, Košice, Technická univerzita v Košiciach 2020, 308 p.

3. Guzanová, A. et al.: A study of the effect of surface pre-treatment on the adhesion of coatings, Journal of Adhesion Science and Technology 2014, 28, 1-18.

4. Brezinová J., Guzanová, A., Draganovská D.: Surface mechanical (Physical) Treatments Prior to Bonding, Handbook of Adhesive Technology, New York, CRC Press Taylor and Francis Group, 2018, 19-66.

5. Herbath B., Kovacs K.: The effects of the steel's surface quality on the properties of anti-corrosion coatings, IOP Conf. Series: Materials Science and Engineering 2020, 903, $1-8$.
6. Narayanan T.S.N.S.: Surface pretreatment by phosphate conversion coatings - A review, Reviews on Advanced Materials Science 2005, 9, 130-177.

7. Pokorný, P.: Předpokládaná účinnost konverzních povlaků proti aktivaci zinkované oceli v modelových pórových roztocích betonu, Koroze a ochrana materiálu 2013, 57, 115-126.

8. Burduhos-Nergis D.P. et al.: Evaluation of the Corrosion Resistance of Phosphate Coatings Deposited on the Surface of the Carbon Steel Used for Carabiners Manufacturing, Applied Sciences 2020, 10, 2753.

9. Abdalla K., Rahmat A., Azizan A. The effect of pH on zinc phosphate coating morphology and its corrosion resistance on mild steel, Advanced Materials Research 2013, 626, 569-574.

10. Zhao X. et al.: Corrosion resistance of concrete reinforced by zinc phosphate pretreated steel fiber in the presence of chloride ions, Materials 2020, 13, 3636.

11. Sinha P. K., Feser R.: Phosphate coating on steel surfaces by an electrochemical method, Surface and Coatings Technology 2002, 161, 158-168.

12. Jegannathan S. et al.: Formation of zinc phosphate coating by anodic electrochemical treatment, Surface and Coatings Technology 2006, 200, 6014-6021.

13. Matuška M., Kučerová M.: Moderní trendy v kataforéze, Povrchové úpravy 2018, 2, 15-18. 